\title{
An Attentional Bias for Occasional Cellphone Users Assessed with the Emotional Stroop Test
}

\author{
Antonio A. Álvarez* and Lucía Otero \\ Departamento de Psicología Social, Básica y Metodología, Universidad de Santiago de Compostela, Santiago de \\ Compostela, Spain \\ Email: antonio.alvarez.cruz@usc.es
}

\begin{abstract}
The use of the cellphone has drastically increased in the last few years, which entails a risk for owners that their excessive use may produce an addiction. When someone develops this dependence, they tend to show an attentional bias to information related to it. The abovementioned hypothesis has been investigated in this study using an addiction Stroop test. In light of this, 43 undergraduates, classified as high or low message senders according to their daily average, were requested to perform a Stroop task including cellphone-related, toothache-related (control condition) and neutral words. No cellphone-related attentional bias was found, but the less frequent users were faster with toothache-related words than with neutral words. Analyzing the whole sample, this Stroop facilitation effect significantly and negatively correlated with cellphone usage frequency. No evidence of a cellphone-related addiction was found, but the results indicate that cellphone use may be associated with attentional biases.
\end{abstract}

Keywords: Cellphone use frequency, addiction stroop test, attentional bias, toothache-related stroop facilitation effect.

\section{Introduction}

The Addiction Stroop Test is a specialization of the Emotional Stroop Test used to investigate biases related to addictive conducts. As with the general paradigm, the participants have to indicate the colour of words presented in each trial. These words can have a special connotation (i.e., emotional meaning), or be neutral, the performance before the affective words being compared with that of the neutral words. If the reaction times (RTs) are longer for affective words than neutral ones (emotional Stroop interference), this is interpreted as a more detailed processing of the affective words, derived from the vigilance or "hyper-vigilance" (Roelofs, Peters, \& Vlaeyen, 2002) of the issues that they represent. On the contrary, if RTs are faster for affective words than neutral ones (emotional Stroop facilitation), this may reflect a more superficial processing of the affective words, due to their avoidance of the contents to which they refer (Klein \& Knäuper, 2009). By means of this method, attention biases have been found related to cannabis (e.g., Cousijn et al., 2013), alcohol (e.g., Fadardi \& Cox, 2006), cocaine (e.g., Liu et al., 2011), heroine (e.g., Marissen et al., 2006), gambling (e.g., Boyer \& Dickerson, 2003), and online shopping (Jiang, Zhao, \& Li, 2017).

The use of cellphones has drastically increased in the last few years. It has been estimated that four and a half thousand million people utilize the cellphone worldwide (Goswami \& Singh, 2016). Many European countries have more cellphone subscriptions than inhabitants (Swiss Federal Statistics Office, 2014, in Billieux, Maurage, López-Fernández, Kuss, \& Griffiths, 2015), and Asia even has twice as many (Office of the Communication Authority of Hong-Kong, 2013, in Billieux et al., 2015). This use carries a series of positive effects for the users, such as the increase in communication and social relations, but it also may have other adverse effects, like the lack of students' concentration during school activities, or the partaking of dangerous practices such as using the handset at the wheel (Hong, Chiu, \& Huang, 2012; Walsh, White, Cox, \& Young, 2011). In addition, it is essential to consider that the excessive use of cellphones may give rise to an addiction that, as occurs in substance dependence, involves harmful effects for behaviour such as loss of control or withdrawal symptoms (e.g., Aggarwal, Grover, \& Basu, 2012; Goswami \& Singh, 2016). This issue is, nevertheless, under controversy with researchers holding 
opinions across a broad spectrum (De Sola-Gutiérrez, Rodríguez de Fonseca, \& Rubio, 2016) ranging from those who consider problematic cellphone use as an addiction (or other psychopathological problem) to those who see it as merely a conduct reflecting a certain lifestyle. Billieux et al. (2015) have highlighted the lack of evidence that psychological and neurobiological mechanisms underlying recognized substance and behavioural addictions are also present in the etiology of problematic cellphone use. When someone develops an addiction (e.g., to a substance), they tend to show an attentional bias to information related to it (Cox, Fadardi, \& Pothos, 2006). Such a bias can be assessed with an addiction Stroop test (the most widely used paradigm for doing this; Cox et al., 2006), although explanations for said bias have been elusive.

Pothos and Tapper (2010) have distinguished three possible causes of the bias: one proceeds from the incentive salience theory (e.g., Robinson \& Berridge, 1993) and proposes that the brain becomes sensitized to substance-related information in such a way that a word's meaning captures attention in detriment of the processing of other perceptual properties of words; another possible explanation comes from the motivational approach (e.g., Cox \& Klinger, 2004) and suggests that, considering that everybody is involved in goal pursuit, the bias would be the result of attending towards and processing environmental cues in order of importance associated with the particular goal of substance consumption; the third explanation is cognitive (e.g., Tiffany, 1990) and asserts that frequent substance consumption gives rise to automatic association between the substance and corresponding expectancies, related concerns and so on. These are activated by the substance-related stimuli, resulting in the activation of other information which increases cognitive load, and thus producing a temporary bottleneck in cognitive processing which delays colour responding (Pothos \& Tapper, 2010).

In any case, it appears that a complete explanation of the addiction-related attentional bias should include emotional, motivational and cognitive factors (Cox et al., 2006).

Although to find a compelling account of addiction-related biases is of great interest, the main objective of this study was not to contrast different theories proposed so as to explain them [see Cox et al. (2006), for a review], but to investigate whether the more frequent use of cellphones is associated with an attentional bias in a cellphone-related Stroop test (a first, to the authors' knowledge). A positive result might constitute evidence supporting the proposal that excessive or problematic cellphone use is an addictive form of behaviour.

\section{$2 \quad$ Method}

\subsection{Participants}

The sample was composed of 43 Psychology students (34 of whom were women) from the University of Santiago de Compostela, Spain, whose ages ranged between 17 and 25 ( $M=19.35$; SD: 2.09), and who kindly accepted the invitation to collaborate in the investigation in exchange for a symbolic reward (some candies). They were unaware of the objectives of the study.

\section{$2.2 \quad$ Instruments}

In order to classify the sample according to their frequency of cellphone usage, a paper-and-pen demographic questionnaire was administered to the participants. It included questions on demographic information (gender, age, etc.), colour discrimination, and other questions about the average number of phone calls made and text messages sent daily, as well as how the participants used their devices. In addition, other questions were included (e.g., frequency of dental appointments and physical activity) in order to hide the true objective of the study.

In the Stroop task, the presentation of stimuli and recording of responses was carried out with four Intel Pentium D CPU 2.66 GHz personal computers (PCs), connected to LCD Hyundai ImageQuest N71S 17" monitors. The experiment was programmed and run by means of E-Prime 2.0 software (Schneider, Eschman, \& Zuccolotto, 2002). The stimuli were 60 Spanish words presented in blue or red, 18-point Courier New typeface against a white background. From those words, 15 were cellphone-related (e.g., in English, MOBILE) and other 15 toothache-related (e.g., CARIES). For each one of these words, another word with the same length, similar frequency of use, unrelated to those topics, and emotionally 
neutral was presented (e.g., TENNIS). In addition, 15 neutral words were used in a practice phase for the participants to become familiarized with the task. The words were selected from the Corpus de Referencia del Español Actual (CREA), a tool provided by Real Academia Española (RAE) on its web page, where lists of words sorted by frequency are displayed. The words used in the experimental phase of the Stroop task are shown in Table 1.

\subsection{Procedure}

The sessions were individual and conducted in four cubicles, each one illuminated with two Philips PL-C cluster 4-pin $26 \mathrm{~W}$ fluorescent lamps. The participants sat in front of the monitors and read the onscreen instructions. These indicated that their task would consist on pressing one of two keys marked either with a red (key 1 of the numeric keypad) or blue patch (key 2), according to the colour of the word that was displayed in every trial. To become familiarized with the task, the participants initially performed 30 trials with 15 neutral words, each with either red or blue fonts. At the end of the practice phase, the participants carried out the experimental task that consisted of 120 trials of 15 cellphonerelated words, 15 neutral words matched in length and frequency with them, 15 toothache-related words, and 15 neutral words matched with them. The words were presented sequentially in a non-blocked, randomized order, each of the words being presented twice, one trial in red and the other one in blue. For each trial, participants focused on a cross at the centre of screen for $1000 \mathrm{~ms}$, as a fixation point, which was consequently substituted by a word that remained on screen until response. After that, feedback was shown either with the message "Correcto!" along with the RT and the current percentage of hits, or the message "Incorrecto" or "No response detected", depending on the result. The participants pressed the keyboard space bar to start each test phase. After finishing the task, the participants were asked to answer the demographic questionnaire, and finally, were thanked and offered some candies as a symbolic payment for their selfless collaboration.

Table 1. Words presented in the Stroop task of the experiment along with their values of frequency of use in the CREA.

\begin{tabular}{llll}
\hline Cellphone-Related Words & $\begin{array}{l}\text { Absolute/Normalized } \\
\text { Frequency }\end{array}$ & Neutral Words & $\begin{array}{l}\text { Absolute/Normalized } \\
\text { Frequency }\end{array}$ \\
\hline NÚMERO(number) & $45,985 / 301.42$ & CENTRO(center) & $45,456 / 297.95$ \\
CONTACTO(contact) & $13,227 / 86.7$ & CAPÍTULO(chapter) & $12,887 / 84.47$ \\
APLICACIÓN(application) & $12,947 / 84.86$ & ANTERIORES(previous) & $13,350 / 87.5$ \\
LLAMADA(call) & $12,090 / 79.24$ & PÁGINAS(pages) & $12,072 / 79.13$ \\
MENSAJE(message) & $10,836 / 71.02$ & OBJETOS(objects) & $10,786 / 70.7$ \\
RECIBIDO(received) & $9,110 / 59.71$ & APARECEN[(they)appear] & $9,136 / 59.88$ \\
PANTALLA(screen) & $6,648 / 43.57$ & DESPACHO(office) & $6,756 / 44.28$ \\
ENVIADO(sent) & $5,765 / 37.78$ & TERCERO(third) & $5,755 / 37.72$ \\
CONEXIÓN(connection) & $3,559 / 23.32$ & CONCRETA(specific) & $3,555 / 23.3$ \\
COBERTURA(reception) & $3,329 / 21.82$ & BRASILEÑO(Brazilian) & $3,328 / 21.81$ \\
PERDIDA[missed(call)] & $3,308 / 21.68$ & SERVIDO(served) & $3,309 / 21.69$ \\
MÓVIL(cellphone) & $2,863 / 18.76$ & TENIS(tennis) & $2,862 / 18.76$ \\
CONTESTAR(to answer) & $2,172 / 14.23$ & CAMBIANDO(changing) & $2,171 / 14.23$ \\
TARIFA(tariff) & $1,790 / 11.73$ & BUQUES(ships) & $1,788 / 11.72$ \\
BATERÍA(battery) & $1,425 / 9.34$ & PONEMOS[(we)put] & $1,425 / 9.34$ \\
& & & \\
Toothache-Related Words & & & \\
DIENTES(teeth) & & & \\
DAÑO(damage) & $6,519 / 42.73$ & POSTURA(posture) & $5,542 / 42.88$ \\
INFLAMACIÓN(infflamation) & $938 / 6.14$ & PASE(pass) & $538 / 6.14$ \\
IMPLANTES(implants) & $750 / 4.91$ & CONSECUTIVO(consecutive) & $750 / 4.91$ \\
DENTISTA(dentist) & $518 / 3.39$ & ALQUILAR(to rent) & 5.39 \\
\hline
\end{tabular}




\begin{tabular}{llll} 
PERFORACIÓN(perforation) & $455 / 2.98$ & POLITÉCNICA(polytechnic) & $455 / 2.98$ \\
MUELAS(molars) & $388 / 2.54$ & HÉLICE(propeller) & $388 / 2.54$ \\
BUCAL(buccal) & $372 / 2.43$ & MUSGO(moss) & $373 / 2.44$ \\
ANTIBIÓTICO(antibiotics) & $327 / 2.14$ & PRACTICANTE(practicing) & $327 / 2.14$ \\
DOLIENTE(aching) & $323 / 2.11$ & PINCELES(paintbrushes) & $323 / 2.11$ \\
CARIES(caries) & $275 / 1.80$ & EMBUDO(funnel) & $275 / 1.80$ \\
ANALGÉSICO(painkiller) & $191 / 1.25$ & CONCORDATO(concordat) & $191 / 1.25$ \\
EMPASTE(filling) & $82 / 0.53$ & SECUNDA[(she/he)supports] & $82 / 0.53$ \\
FLEMÓN(gum boíl) & $39 / 0.25$ & PLEURA(pleura) & $39 / 0.25$ \\
ENDODONCIA(root canal) & $9 / 0.05$ & GALERISMO(art gallery Studies) & $9 / 0.05$ \\
\hline
\end{tabular}

\section{Results}

In order to divide the sample according to cellphone use frequency, the number of messages sent daily was taken as the base. In the demographic questionnaire, this question asked participants to select the interval that best represented their approximate average number of messages sent daily from the following ranges: "2 and 5", "6 and 10", "11 and 30", "31 and 60", and "61 and 100", as well as "more than 100". To make operative these intervals, they were converted into their means, that is, 3.5, 8, 20.5, 45.5, and 80.5, respectively, the last interval being represented by 100 . The mean cellphone use frequency of the sample was 65.01 and the median, 80.5. Therefore, participants with more than 60 messages sent daily (25 participants, 20 women) were assigned to the high-use frequency group, whereas participants with less than 61 messages sent daily (18 participants, 14 women) were assigned to the lowuse frequency group. A correlation analysis between cellphone use frequency and age obtained a significant negative correlation $(r=-.36 ; p<.02)$.

The mean RTs (SDs between parentheses) and percentages of hits of the emotional Stroop task are shown in Table 2.

Table 2. Mean RTs (SDs between parentheses) and percentages of hits for the cellphone-use frequency group (high, low), thematic (cellphone, toothache), word category (neutral, emotional), and word colour (blue, red).

\begin{tabular}{lllll}
\hline \multicolumn{4}{c}{ High Use Frequency Group } \\
\hline & Neutral Words & Emotional & Words \\
\hline Cellphone & Blue & Red & Blue & Red \\
& $419(61)$ & $425(58)$ & $416(52)$ & $421(58)$ \\
Toothache & .973 & .986 & .980 & .986 \\
& $421(71)$ & $418(54)$ & $426(61)$ & $422(62)$ \\
& .970 & .984 & .978 & .983 \\
\hline Cellphone & $412(60)$ & $402(63)$ & $400(65)$ & $408(67)$ \\
& .974 & .977 & .989 & .977 \\
Toothache & $414(63)$ & $424(72)$ & $406(66)$ & $400(56)$ \\
& .984 & .973 & .981 & .973 \\
\hline
\end{tabular}

\subsection{Accuracy}

An ANOVA 2(cellphone use frequency group: high, low) x 2(Stroop thematic: cellphone, toothache) $\mathrm{x}$ 2(word category: neutral, emotional) x 2(word colour: blue, red) with the percentages of hits, the first variable between-groups and the rest within-subjects, only found a significant effect for the frequency group x colour interaction $\left(F(1,41)=4.58 ; p<.05 ; \eta^{2}=.10\right)$. Post-hoc comparisons with the Bonferroni's test indicated that the participants of the high frequency group tended $(p=.065)$ to be more accurate in responding to words in red $(\mathrm{M}=.985)$ than in blue $(\mathrm{M}=.975)$. 


\subsection{Latency}

An ANOVA 2(frequency group) x 2(Stroop thematic) x 2(word category) x 2(word colour) with RTs to correct responses, the first between-groups variable, the rest within-subjects, only found residually significant effects for the interactions of frequency group $\mathrm{x}$ word category $(F(1,41)=2.95 ; p=.09$; $\left.\eta_{\mathrm{p}}^{2}=.07\right)$ and of frequency group $\mathrm{x}$ thematic $\mathrm{x}$ word category $\left(F(1,41)=2.82 ; p=.10 ; \eta_{\mathrm{p}}^{2}=.06\right)$. Post-hoc comparisons indicated that the low-frequency cellphone users were quicker $(p<.02)$ to respond to toothache-related words rather than neutral words (see Table 2), whereas the higher-frequency cellphone users did not show any significant differences $(p=.43)$. Fifteen out of the 18 less-frequent cellphone users $(83 \%)$ showed the toothache-related Stroop facilitation effect, whereas 12 out of the 25 more-frequent cellphone users $(48 \%)$ did so. A $t$-test for independent samples was used to determine whether there was a difference in this effect between the two frequency groups. The Levene Contrast showed that the population variances of the two groups were not different $(F=0.91 ; p=.35)$. Assuming such an equality, the measure indicated $(t(41)=2.56 ; p<.02)$ that the participants who used less frequently the cellphone had a greater bias than those who did so more frequently. This difference is illustrated in Figure 1.

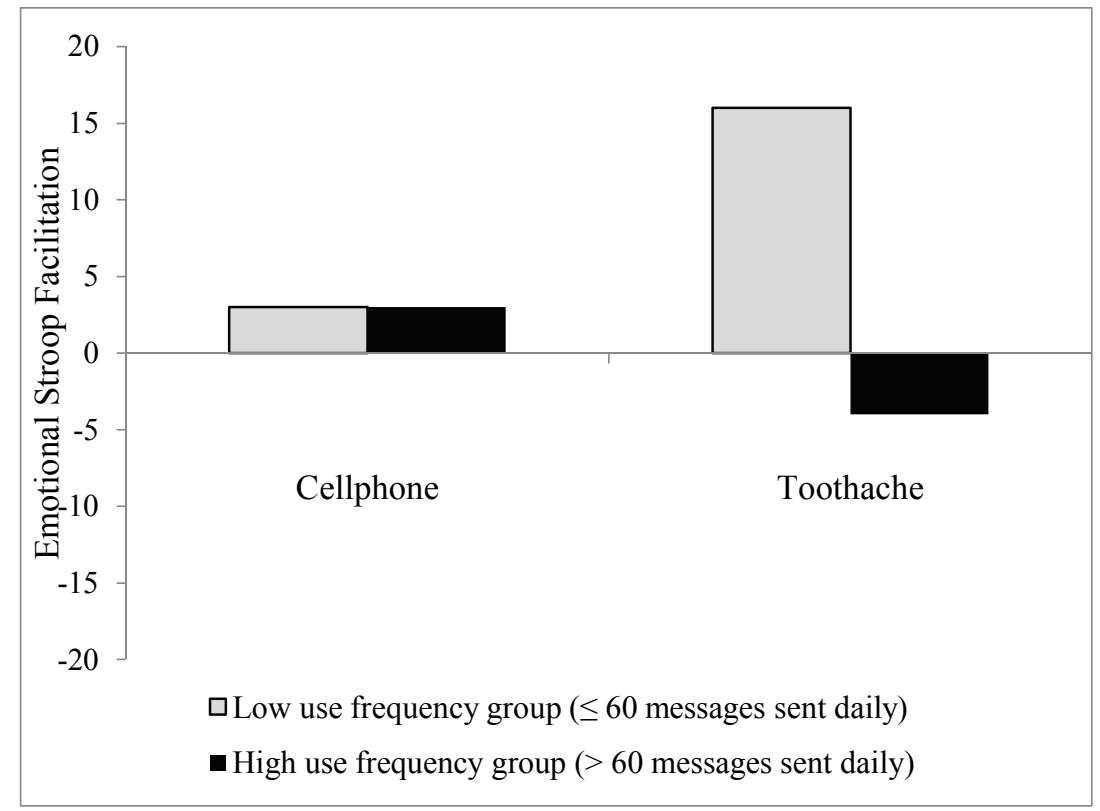

Figure 1. Emotional Stroop facilitation effect $\left(R \mathrm{~T}_{\text {neutral }}-\mathrm{RT}_{\text {emotional }}\right)$ for each cellphone use frequency group (high, low), and thematic (cellphone, toothache) in the Stroop task of the experiment.

To investigate a possible relationship between this toothache-related Stroop facilitation effect and cellphone use frequency, a correlation analysis was performed with the Spearman's rho test. A significant negative correlation was found $(\rho=-.44 ; p<.004)$. Figure 2 illustrates this finding.

\section{Discussion}

As far as the authors know, this is the first study where a cellphone-related attentional bias (CRAB) was investigated by using an addiction Stroop task. In order to do so, a sample of college students, divided into two groups according their cellphone usage frequency, were asked to perform a Stroop task which included cellphone-related and neutral words matched in length and frequency of use, as well as toothache-related and matched neutral words, serving as a control condition. The results did not show any evidence of a CRAB, but there was an unexpected toothache-related Stroop facilitation effect in the group of low-frequency cellphone users.

In summary, it appears that as with other conducts or interests, cellphone use may produce related attentional biases, but, at least in this study, they do not indicate any dependent or addictive behaviour. 
Several methodological issues emerge from an analysis of this study, which could have had influence on the results. One of these is the procedure of assessing the cellphone use frequency. This was measured through a self-report question asking about the approximate average of messages sent daily, relying on the participants' memory and, therefore, potentially being biased or wrong. This estimate was included in a demographic questionnaire, camouflaged among other questions in order to avoid alerting the participants about the main goal of the experiment. Perhaps a more objective assessment of cellphone use frequency in future experiments, might be obtained by sending the demographic questionnaire to participants a few days before the experimental sessions, and asking them to record the number of messages sent in each of the (e.g.) three days prior to their participation in the experiment. A mean of the three numbers would be a rather accurate (not approximate) figure that directly represents participants' cellphone usage frequency.

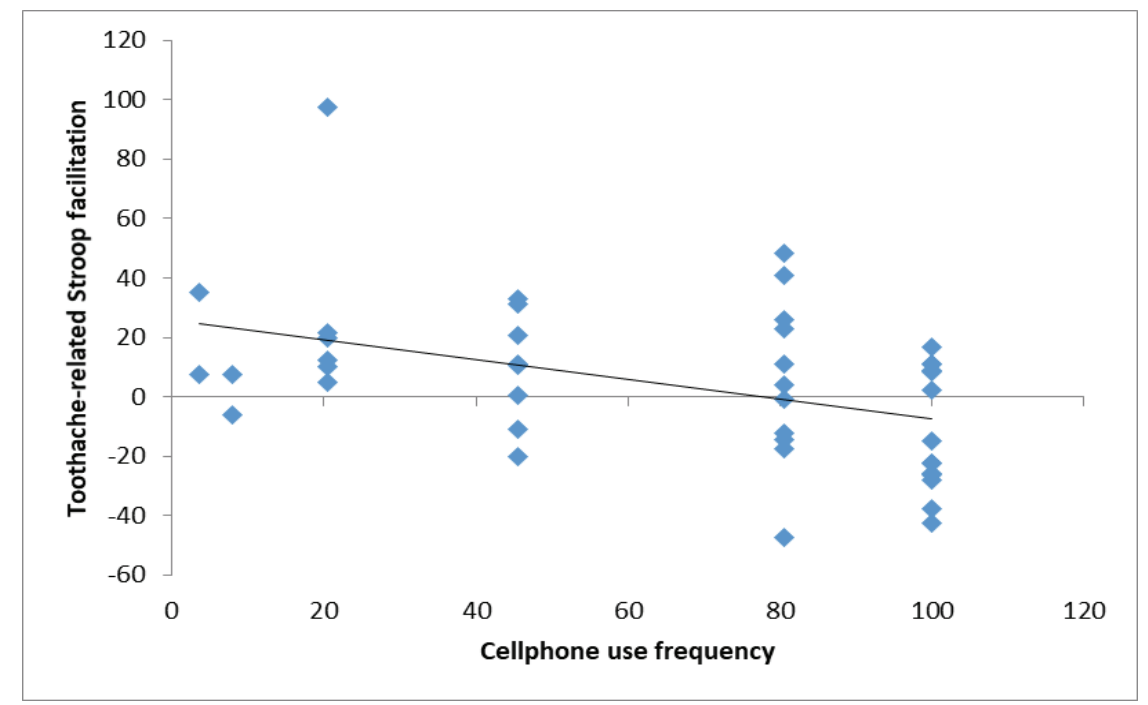

Figure 2. Dispersion graph describing the relationship between cellphone use frequency and the toothache-related Stroop facilitation effect found in the experiment.

In addition to the previous issue the way which the sample was divided into a high-use and a low-use frequency group may be put into question. This was conducted in a very simple way in this study, classifying those participants who sent the same as or a lesser number of messages daily than the sample mean as the low-use frequency group, and the other participants (sending a higher number of messages than the sample mean) as the high-use frequency group. A more restrictive method to split the sample could have been used, for instance, taking only the participants whose number of messages sent daily was at least one standard deviation (SD) above or below the sample mean ("the 1 SD rule", e.g., Castano et al., 2011). Nevertheless, neither this nor other restrictive procedure were used in order to prevent too many participants from being left out of the selection, which bring us to a third methodological issue to be considered: the set size. This has been a very exploratory study to investigate whether a recognized and widely used addiction-related paradigm, the modified Stroop task, could be applied to the study of a form of behaviour which has been considered as problematic and even addictive in the last few years. A future experiment will try to replicate the current results with a larger sample, employing a more objective measure to assess the cellphone use frequency, and restricting the analysis to participants whose indices of cellphone use frequency are more distant from the sample mean. If the results in this study are confirmed in future experiments, all of these changes will make it easier to conclude that a CRAB is not present among this segment of youth, a relevant finding considering that they (e.g., people from their late-teens to mid-twenties), more than any other age population, have incorporated cellphones as an integral part of their lives, and, therefore, are at a higher risk than any other age segment when it comes to developing a problematic cellphone use (e.g., Chen et al., 2017; Goswami \& Singh, 2016; Walsh et al., 2011). 


\section{Conclusion}

It has been claimed that the proposal that the excessive use of cellphones is a behavioural addiction is mainly supported by self-report studies (Billieux et al., 2015; De Sola-Gutiérrez et al., 2016). There is a lack of evidence that similar psychological or neurobiological mechanisms underlying in recognized substance and behavioural addictions, are also present in the excessive use of cellphones (Billieux et al., 2015). When a person acquires an addiction, they tend to show an attentional bias to information related to it (Cox et al., 2006), and such a bias can be assessed with an addiction Stroop test (e.g., Boyer \& Dickerson, 2003; Marissen et al., 2006). The results of the current study do not provide evidence of a CRAB. Various reasons may be behind this null result. First of all, perhaps excessive cellphone use may not be conceptualized as a behavioural addiction due to certain specificities of that conduct, such as its relationship to interpersonal processes or the wide range of functions available on smartphones (Billieux et al., 2015; Chen et al., 2017). Unlike the use of recreational drugs, or even gambling, cellphone use is fully integrated into everyday life, where, without an excessive or maladaptive use, may be a practical and functional instrument for human communication. To an extent, its use might be comparable to that of the car, almost essential to enable people's autonomy in modern societies, but which entails significant problems when their use is not controlled. It seems relatively easy to think of an excessive or maladaptive use of car, without the need to emphasize or conceptualize it as a "car addiction".

Another cause which may be behind the null result for the CRAB, might have to do with certain characteristics of the sample that could have influenced on the results, although no indication of this idea is evident. The participants were college students, a typical convenience sample (e.g., Chen et al., 2017; Chiu, Hong, \& Chiu, 2013; Hong et al., 2012), with younger participants using the cellphone more than older participants do (e.g., Bianchi \& Philips, 2005; De Sola-Gutiérrez et al., 2016; Walsh et al., 2011), and with the majority of participants being women, supposedly more inclined to develop a cellphone-related dependence (e.g., Billieux, Van der Linden, \& Rochat, 2008; Chiu et al., 2013). The rates of cellphone usage frequency were too high to fail to reach levels that could be classified as being excessive either: nearly $60 \%$ of the sample reported sending on average more than 60 messages daily, with the most-intensive users stating that they sent more than 100 .

A third cause for the absence of a CRAB is related to the assessment instrument. The Stroop task of this study was expressly designed for this experiment, not having been tested before, which raises doubts about its validity and reliability with respect to this specific attentional bias. However, the instrument has proven to be sensitive enough to detect another, unexpected attention bias: the more occasional cellphone users showed a Stroop facilitation effect associated with the toothache-related words, the control condition. This bias was only significant for the less frequent cellphone users, the great majority of whom showed this bias, whereas the more frequent cellphone users did not show any significant bias. Nevertheless, an analysis of the whole sample found a significant negative correlation between the toothache-related Stroop facilitation scores and the cellphone use frequency ranks. The emotional Stroop facilitation is interpreted as the result of a more superficial processing of affective words, reflecting the avoidance of the contents that they represent (Klein \& Knäuper, 2009). Although not so common as the Stroop interference, the facilitation effect has been registered in studies related to death (FernándezLeón \& Álvarez, 2015), psoriasis (Fortune et al., 2003), tinnitus (Andersson, Bakhsh, Johansson, Kaldo, \& Carlbring, 2005), mental illness self-stigma (Chan \& Mak, 2015), and violence (Smith \& Waterman, 2005). An inverse correlation between avoidance of toothache-related cues and frequency of cellphone use might call to our attention the controversial debate about the effects of cellphone on health.

It is thought that exposure to radio frequencies that accompany cellphone use causes a variety of physiological effects, which, however small they may be, makes this stimulation a non-natural stressor of the biological system (Matta \& Burkhardt, 2003). For instance, evidence has been found that proximity to a cellphone alters the electrical activity of brain. Thus, Croft et al. (2008), in a double-blind experiment, placed either an active or turned-off cellphone over the temporal region of the participants' heads, to then record their electroencephalographic activity (EEG). Exposure to the switched-on cellphone increased EEG activity in the alpha frequency range, especially in ipsilateral head locations. In another study, Ferreri et al. (2006) found that the continuous flow of electromagnetic stimulation caused by a cellphone affected the excitability of the motor cortex adjacent to the source of stimulation. Closer 
to the toothache-related Stroop facilitation effect is Yadav and Sharma's (2008) study, which investigated whether electromagnetic radiation emitted by cellphones, produced effects on epithelial cells of the mouth. In order to do this, the authors employed the micronucleus assay, a test that accounts for anomalous citoplasmatic bodies that may be produced by exposure to genotoxic agents. By using this test with a group of cellphone users (a mean time of 2.35 years) and a control group of non-users, Yadav and Sharma found that the users had a greater number of micronucleated cells and of total micronuclei.

Nevertheless, no conclusive results have been found that demonstrate the connection between a specific risk to health and the continued use of the devices, in part, because most published epidemiological studies do not cover long enough periods of time to demonstrate chronic effects associated with a long-term use of the cellphone (Matta \& Burkhardt, 2003; Yadav \& Sharma, 2008). From this angle, perhaps the Emotional Stroop Test, not subject to sources of error that commonly affect self-reports (Channon \& Hayward, 1990), and with not only a diagnostic but also a prognostic value of behavioural and physiological variables (e.g., Cha et al., 2010; Marissen et al., 2006; Munafò \& Stevenson, 2003), could provide valuable information about the effects of cellphone use on health, other than the likelihood of developing an addiction.

\section{References}

1. M. Aggarwal, S. Grover, and D. Basu (2012), "Mobile phone use by resident doctors: tendency to addiction-like behavior," German journal of psychiatry, vol. 15, no. 2, pp. 50-55.

2. G. Andersson, R. Bakhsh, L. Johansson, V. Kaldo, and P. Carlbring (2005), "Stroop facilitation in tinnitus patients: an experiment conducted via the World Wide Web," CyberPsychology \& behavior, vol. 8, no. 1, pp. $32-38$.

3. Bianchi and J. G. Phillips (2005), "Psychological predictors of mobile use," CyberPsychology \& behavior, vol. 8, no. 1, pp. 39-51. DOI: $10.1089 /$ cpb.2005.8.39.

4. J. Billieux, P. Maurage, O. López-Fernández, D. J. Kuss, and M. D. Griffiths (2015), "Can disordered mobile phone use be considered a behavioral addiction? An update on current evidence and a comprehensive model for future research," Current addiction reports, DOI 10.1007/s40429-015-0054-y

5. J. Billieux, M. Van der Linden, and L. Rochat (2008), "The role of impulsivity in actual and problematic use of the mobile phone," Applied cognitive psychology, vol. 22, pp. 1195-1210. DOI: 10.1002/acp.1429

6. M. Boyer and M. Dickerson (2003), "Attentional bias and addictive behavior: automaticity in a gamblingspecific modified Stroop task," Addiction, vol. 98, pp. 61-70.

7. E. Castano, B. Leidner, A. Bonacosa, J. Nikkah, R. Perrulli, B. Spencer, and N. Humphrey (2011), "Ideology, fear of death, and death anxiety," Political psychology, vol. 32, no. 4. Doi: 10.1111/j.1467-9221.2011.00822.x

8. B. Cha, S. Najmi, J. M. Park, C. T. Finn, and M. K. Nock (2010), "Attentional bias toward suicide-related stimuli predicts suicidal behavior," Journal of abnormal psychology, vol. 119, no. 3, pp. 616-622. DOI: $10.1037 / \mathrm{a} 0019710$

9. K. K. S. Chan and W. W. S. Mak (2015), "Attentional bias associated with habitual self-stigma in people with mental illness," PLoS ONE, vol. 10, no. 7, e0125545. doi:10.1371/journal.pone.0125545

10. S. Channon and A. Hayward (1990), "The effect of short-term fasting on processing of food cues in normal subjects," International journal of eating disorders, vol. 9, no. 4, pp. 447-452.

11. Chen, F. Liu, S. Ding, X. Ying, L. Wang, and Y. Wen (2017), "Gender differences in factors associated with smartphone addiction: a cross-sectional study among medical college students," BMC psychiatry, vol. 17, no. 341. DOI: $10.1186 / \mathrm{s} 12888-017-1503-\mathrm{Z}$

12. S. I. Chiu, F. Y. Hong, and S. L. Chiu (2013), "An analysis on the correlation and gender difference between college students' Internet addiction and mobile phone addiction in Taiwan," ISRN Addiction, pp. 1-10. DOI: $10.1155 / 2013 / 360607$

13. J. Cousijn, P. Watson, L. Koenders, W. A. M. Vingerhoets, A. E. Goudriaan, and R. W. Wiers (2013), "Cannabis dependence, cognitive control and attentional bias for cannabis words," Addictive behavior, vol. 38, pp. 2825-2832. http://dx.doi.org/10.1016/j.addbeh.2013.08.011

14. W. M. Cox, J. S. Fadardi, and E. M. Pothos (2006), "The Addiction-Stroop Test: Theoretical considerations and procedural recommendations," Psychological bulletin, vol. 132, no. 3, pp. 443-476. DOI: 10.1037/00332909.132.3.443

15. W. M. Cox and E. Klinger (2004), "A motivational model of alcohol use: Determinants of use and change," in 
Handbook of motivational counseling: Concepts, approaches, and assessment. Wiley, pp. 121-138.

16. CREA. Corpus de referencia del español actual, Real Academia Española, Available: http://www.rae.es

17. R. J. Croft, D. L. Hamblin, J. Spong, A. W. Wood, R. J. McKenzie, and C. Stough (2008), "The effect of mobile phone electromagnetic fields on the alpha rhythm of human electroencephalogram," Bioelectromagnetics, vol. 29, pp. 1-10. doi: 10.1002/bem.20352

18. J. De Sola-Gutiérrez, F. Rodríguez de Fonseca, and G. Rubio (2016), "Cell-phone addiction: a review," Frontiers in psychiatry, 7, doi: 10.3389/fpsyt.2016.00175

19. J. S. Fadardi and W. M. Cox (2006), "Alcohol attentional bias: drinking salience or cognitive impairment?," Psychopharmacology, vol. 185, pp. 169-178. DOI 10.1007/s00213-005-0268-0

20. I. Fernández-León and A. A. Álvarez (July 2015), "A Stroop facilitation effect for death cues". Poster presented at the $14^{\text {th }}$ European Congress of Psychology, Available: www.ecp2015.it/wp-content/uploads/2015/06/ PostersECP2015.pdf (P609)

21. F. Ferreri, G. Curcio, P. Pasqualetti, L. De Gennaro, R. Fini, and P. M. Rossini (2006), "Mobile phone emissions and human brain excitability," Annals of neurology, vol. 60, pp. 188-196.

22. G. Fortune, H. L. Richards, A. Corrin, R. J. Taylor, C. E. M. Griffiths, and C. J. Main (2003), "Attentional bias for psoriasis-specific and psychosocial threat in patients with psoriasis," Journal of behavioral medicine, vol. 26, no. 3, pp. 211-224.

23. V. Goswami and D. R. Singh (2016), "Impact of mobile phone addiction on adolescent's life: A literature review," International journal of home science, vol. 2, no. 1, pp. 69-74.

24. F.-Y. Hong, S.-I. Chiu, and D.-H. Huang (2012), "A model of the relationship between psychological characteristics, mobile phone addiction and use of mobile phones by Taiwanese university female students," Computers in human behavior, http://dx.doi.org/10.1016/j.chb.2012.06.020

25. Z. Jiang, X. Zhao, and C. Li (2017), "Self-control predicts attentional bias assessed by online shopping-related Stroop in high online shopping addiction tendency college students," Comprehensive psychiatry, vol. 75, pp. 1421. http://dx.doi.org/10.1016/j.comppsych.2017.02.007

26. R. Klein and B. Knäuper (2009), "Predicting attention and avoidance: When do avoiders attend?," Psychology and health, vol. 24, no. 7, pp. 729-747. DOI: 10.1080/08870440801947779

27. S. Liu, S. D. Lane, J. M. Schmitz, A. J. Waters, K. A. Cunningham, and F. G. Moeller (2011), "Relationship between attentional bias to cocaine-related stimuli and impulsivity in cocaine-dependent subjects," The american journal of drug and alcohol abuse, vol. 37, pp. 117-122. DOI: 10.3109/00952990.2010.543204

28. M. A. E. Marissen, I. H. A. Franken, A. J. Waters, P. Blanken, W. van den Brink, and V. M. Hendriks (2006), "Attentional bias predicts heroin relapse following treatment," Addiction, vol. 101, pp. 1306-1312. doi: 10.1111/j.1360-0443.2006.01498.x

29. C. F. Matta and S. Burkhardt (2003), "Health risks of cellular telephones: the myth and the reality," Ontario Public Health Association (OPHA), pp. 1-20. http://www.opha.on.ca

30. M. R. Munafò and J. Stevenson (2003), "Selective processing of threat-related cues in day surgery patients and prediction of post-operative pain," British journal of health psychology, vol. 8, pp. 439-449.

31. M. Pothos and K. Tapper (2010), "Inducing a Stroop effect," Applied cognitive psychology, vol. 24, no. 7, pp. 1021-1033. doi:10.1002/acp.1603

32. T. E. Robinson and K. C. Berridge (1993), "The neural basis of craving: An incentive-sensitization theory of addiction," Brain research reviews, vol. 18, pp. 247-291.

33. J. Roelofs, M. L. Peters, and J. W. S. Vlaeyen (2002), "Selective attention for pain-related information in healthy individuals: the role of pain and fear," Journal of pain, vol. 6, pp. 331-339. doi:10.1016/S10903801(02)00021-6

34. W. Schneider, A. Eschman, and A. Zuccolotto (2002). E-Prime User's Guide. Psychology Software Tools Inc.

35. P. Smith and M. Waterman (2005), "Sex differences in processing aggression words using the Emotional Stroop task," Aggressive behavior, vol. 31, pp. 271-282. DOI: 10.1002/ab.20071

36. S. T. Tiffany (1990), "A cognitive model of drug urges and drug-use behavior: Role of automatic and nonautomatic processes," Psychological review, vol. 97, pp. 147-168.

37. S. P. Walsh, K. M. White, S. Cox, and R. M. Young (2011), "Keeping in constant touch: The predictors of young Australians' mobile phone involvement," Computers in human behavior, vol. 27, pp. 333-342.

38. A. S. Yadav and M. K. Sharma (2008), "Increased frequency in micronucleated exfoliated cells among humans exposed in vivo to mobile telephone radiations," Mutation research, vol. 650, pp. 175-180. doi:10.1016/ j.mrgentox.2007.11.005 